between the two parties. To prevent such a loss both parties might well co.operate.

If a quarter of the sum lost through nystagmus were spent in continually colouring the mine, and was enough to bring its colour relief up to the level of a lead mine, I do not see why nystagmus should not be abolished, and the other three. duarters of the loss wiped out.

We must remember that it takes sibout twenty jears to produce the disease, and that in a lead mine there is not a great deal of colour. Quite possibly it may not be necessar.y to get as much colour as that.

The net result of suoh a procedure can only be found out by experiment, and one persisted in for a considerable time.

\section{Medical Treatment.}

The first thing to do is to remove the cause; that is, stop work underground. Let the patient rest, and in sub. dued light if he has photophobia.

We have to deal with a state of exhaustion and increased nervous irritability. Therefore at first medical treatment should be sedative; such as the bromides or hyoscyamus.

Later, these should be replaced by stimulant tonics and brighter light as he can tolerate it. To commence with stimulants seems to me like whipping up a tired horse insterd of resting it.

Mechanical.-Eye shades, blue or smoked goggles give a good deal of relief in some cases, especially in sunlight and snow, but fail in othere. I should like to see other coloured goggles tried, particularly green. One man recently told me that when his eyes are very painful he only gets relief on going into a green wood or field.

Proper glasses should be prescribed to correct errors of refraction.

Electrical.-I have not seen any cases that I am aware of being treated by electricity. In chronic intractable cases there seems a fair field for experiment with various forms of electrical treatment.

Special Departments in Hospitals. - Whether it would be profitable to provide green or other coloured rooms, and take in cases as in.patients and apply other special forms of treatment is nncertain. Very likely some way of cutting the disease short conld be discovered; bat, personally, I think better value for the money would be gained by the preventive measures I have indicated.

[An apparatus designed to show the visual effects of lateral nystagmus was exhibited.]

\section{ON THE CAUSE OF NEUROPATHIC} STATES.

By GEORGE RU THERFORD JEFFREY, M.D., M.R C.P.EDIN.

SENIOR ASSISTANT PHYsictan, CRichton Rotal institution, DOMFRJES.

AT the meeting of the Societies of Neurology and Paychiatry in Paris on December 9th, $1909^{1}$ a remark able difference of opinion upon the part played by the emotions in the genesis of neuropathic states was found to prevail among the eminent members who took part in the discussion. In initiating the séance $M$. Déjerine maintained that emotion was the sole cause of neurasthenia ; pointed out that prolonged emotion-not necessarily violent-was more often the canee than emotional shock; and insisted that in the development of neuro. pathic states in the infected, the intoxicated, and the overworked the most active etiological factor was the underlying mental perturbation-the tendency to worry He thus implied that neurastbenics were endowed with a special nervous organization or temperament, which under deleterious inflaences was suitable for the develop ment of neuropathic states. This temperament deter mined the individual's power of self.control in periods of emotional stress; it varied in degree in different individuals, and in the same individual even at different age epochs where the temperament was but feebly present. Neurasthenia, he thought, appeared only after many battles, but self.control survived each encounter with increasing difficulty until the neurasthenic state was fully developed. Such patients are in large measure accidental nearasthenics. An infinite variety of types unites this acquired form to the true constitational neurasthenic. The clinical picture of any case of neurasthenia depends $\in$ ntirely upon his temperament, character, reactions, former affectivity, etc.; hence cases vary, but are all identical in the main features of the disease-the lack of self control in times of emotion.

M. Sollier agreed that the emotions played a funda. mental part in the development of neurasthenia, but thought that in neurasthenia there was a special reac. tion of the nervous system to emotions, which might be constitutional or hereditary, and that the part played by the emotions was only'that of the exciting cause.

Directly opposing those views was M. Babinski, who asserting that such conditions are never the result of shock, added weight to his contention by reporting a series of observations which he made among classes of the community who daily witnessed peoplo exposed to emotional stress. He had interrogated among others the post.mortem attendants of the large Paris hospitals. Some of those sttendant had witnessed as many as 200,000 people identifying in the mortuaries their deceased rela. tives or friends. These people, he contended, had undoubtedly been exposed to great emotional strain. He elicited from the attendants that never had they witnessed amongst all those visitors any who had exhibited an indubitable hysterical attack. He further instances the immunity of the members of the Aero Clab de France from neurasthenic states, and referred to the striking absemce of hysteria found by M. Neri aiter the earthquake at Messina. From these data he concluded that an exag. gerated importance had been conferred upon the rôle of the emotions in the production of neurasthenic states. M. Déjerine, in reply, stated that those who were chosen from the sorrowing housebold to undergo the ordeal of viewing the body were only the strongest and most composed members of the family; the more emotional members remained at home, where they may have had their attrck; and further, it was quite possible that even those members who came to view the remains had passed through an attack before leaving their bome on their painful mission. They did not, however, $\operatorname{com} \theta$ unprepared; they had been tuned up to their ordeal ; and as a parallel he instanced the absence of neuropathic states in soldiers during battle, and its presence in prolonged sieges, involving hardships and privations of all kinds. Not only were those mortaary visitors in a messure prepared for their ordeal, but the amount of shock experienced by them wonld almost certainly vary with the cause of the deatb, whether it had been andden and under tragic circumstances, or a not unexpected result of bad health or old age. M. Babinski's statement seemed to M. Déjerine to show that sudden emotional shocks were not so important as long-continued anxiety. So also the inquiries of M. Neri into the effects produced on the inhabitants at Messina aiter the earthquake, cited by M. Babinski, strengthened M. Déjerine's contention, for as the inhabitants were in a measure forewarned, and as they suffered collectively, not in isolation, there was thas established a resistance which prevented the shock from acting so acutely as it otherwise might have done.

M. Crocq stated that neurasthenia did not essentially demand for its development either an hereditary or a constitutional predisposition, the essential factors in itsproduction being overwork, especially mental, intoxica. tion, and prolonged intense or frequently repeated emotions even of average intensity. To support this statement he cited three cases, one of which, bearing upon the effects of sudden shock, was as follows: An advocate, 55 years of age, whose parents had died of old age, and whose brother and sister were well, was working in his office preparing an interesting "pleading." As he casually and inadvertently looked through the window he saw passing through space his son, who had fallen from the window above. The shock of the socident was such that on the following day the unfortunate parent presented the classical symptoms characteristic of neurasthenia. Neurasthenia, M. Crocq went on to sag, frequently aggravates the immediate results of disasters, especially railway accidents. 
M. Pierre Janet trenchantly criticized the investigations. He asserted that if the same inquiry had been conducted by another than $M$. Babinski the results might have been quite different; he also pointed out that hysterical attacks were not of instantaneous development; that the visitors may have had their attack outside the mortuary, or even at home before or after the viewing of the body; and that those who did come to view the body would certainly be the lesst emotional members of the family. He clearly recognized such a condition as constitutional neurasthenia. That such a condition existed was admitted by M. Vogt, but he was inclined to believe that in the constitutional nearasthenia there was probably as the basis of the malady some defect in cerebral nutrition.

Following him M. Henri Claude, in a few apt words, clearly showed that not only did he agree with M. Déjerine, bat also that he supported M. Sollier in the importance which he attached to the predisposition. This predisposition he pointed out might come from inherited mental degeneracy, but that owing to a series of emotional storms conduced by injudicious education, intellectual overwork-in fact, by long exposure to emotional influences -it could also be acquired. So the discussion proceeded. "Wherever and on whatever questions good men are found ranged on opposite sides, one of three alternatives is always true: Either the points of disagreement are purely speculative and of no moral importance-or there is a misunderstanding of language, and the same thing is meant under a difference of words-or else the real trath is different from what is held by any of the disputants, and each is representing some important element which the others ignore or forget." 2

We may now try to discover the truths common to the opposing parties, M. Déjerine and M. Babinski, in this discussion. Let as consider a normal sensory stimulas with a motor expression. The stimulus impinges on a sensory end organ, the changes initiated there are trans. ferred along an afferent nerve to a central nerve cell, where they excite an activity which is conducted by means of an efferent nerve to a motor organ, and thus the external response of the organism to the sensory stimulus follows. To the same stimulus the same motor response will invariably be given so long as the sensory motor arc is intact. Response to each stimulus is accompanied by electrical and chemical changes, and too frequently repested, too violent, or too prolonged stimulation may induce fatigue and impair the delicacy and the integrity of the primitive reflex arc. If now we interpose one synapse in the afferent and another in the efferent track, so that an alternative course is provided both for theingoing stimulus and the outflowing response, then, if the arc be functioning normally, the sensory stimulus flows in a definite direc. tion-as does the motor response also-for the resistances normally offered at each synapse determine the natural direction of the nerve flow; the current flowing in the natural direction is proceeding along the path of least resistance-that is to say, the resistance in the natural path is normally lower than the resistance in the alternative path.

According to MoDougall's theory, fatigue exerts its protective influence by elevating the resistance at the synapse, so as to block the normal course of the nerve current, and thus in the afferent path inhibit it reaching the cognate central perceptive centre; or under circum. stances, such as excessive fatigue, a point may even be reached where the current may thus be diverted to an alternative path, led to an unnatural central perceptive centre, and so induce an unusual response. It in the efferent track any morbid process effects the same heightening of resistance at the synapse as does fatigue, then, although a sensory stimulus may be correctly perceived and inter. preted, no response, an abortive response, or an unexpected response results - such as may be seen in the negativism of dementis praecox. What is true for a simple reflex arc also applies to the medley of stimuli which constitute everyday sensations, so, under conditions such as morbid degrees of fatigue, unusual perceptive centres may be linked up with sensory impulses to which they are unaccustomed, and only remotely allied, and thus unnatural external responses resalt.

Lesions in the sensory end organs are of little concern to us. Undoubtedly pathological states in the Schneiderian membrane, in the retinal layers, or in the anditory apparatus, may cause peripheral perversion of sensations, and may be the starting point of false conceptions of smell, sight, and hearing, and, similarly, morbid changes may arise in the muscular, glandular, or other peripheral mechanism of emotional expression, but the lesions commonly encountered in psychiatry are situated centrally, either in the perceptive centre or in the afferent or efferent track.

A disease such as hysteria is obviously a lesion of the highest perceptive centres; the stocking, glove, band, or section of limb areas of anaesthesia, or the well-known complete sensory loss on one side of the body, do not correspond to any known area of distribution of peripheral nerves, nor are they limited to the sphere of influence of any nerve roots. The stimulus in such cases is correctly convejed by the sense end organ, by the peripheral nerves, through the spinal cord, medulla, pons, mid-brain, optic thalamus; but somewhere above this point the stimulus is completely blocked-in fact, the area which is insensitive seems to be cat off from its representation in the cortical psychic centres. This isolation may affect not only cataneous stimuli but also the stimali of the special senses, particularly vision.

A hysterical subject who when tested with the peri. meter exhibits only a microscopic field of vision can thread his way through a crowded room; his visual perception mast be functioning subconsciously to enable him to aroid the obstacles, and is probably intact. The lesion in hysteria therefore cannot be a lesion of the primary perceptive centre; the interruption must be situated between the primary perceptive centre and the higher psychic centres.

Such areas of anaesthesia are typically inconstant in size; the mere advance or recession of the anaesthetic boundary denotes only that the continuity of the sensory stimuli is preserved to a lower or higher level, but does not indicate that the sense impreseion then attains to the highest psychic centre which would be its destination if the brain was functioning normally. This highest centre, the seat of intellectual control or judgement, is necessarily the recipient of myriads of stimuli reflected from all parits. of the brain, which have been roused to activity by the sense impression; in other words, the primary stimalus reaches the highest psychic centre enormously reinforced, multiplied, and embellished, and in a corresponding fashion intermediate psychic centres between the highest level and the primary perceptive centre are affected, but in direct ratio to their level-the higher the level the greater is the number of stimuli referred to them, the lower the level the less-antil the primary perceptive centre, the lowest of all, is subjected merely to the activity of the initial stimulus. As the cells in the highest psychic levels are subjected to more stimuli than those at lower levels, the resistance at the synapses of the cells of the highest psychic level will earliest reach a point which stimuli find difficulty in overcoming - that is, fatigue first appears there, and, if the excitation be continued, the stimuli may be entirely blocked; later the process passes down to the lower levels. The blocking of a stimulus at a synapse may not be complete, but what passes the synapse is ineffective in transmitting the original stimulus. Further, the block. ing of the stimulus only implies an interraption for that particular degree of atimulation. But, if the stimulus be slightly increased, the current will again pass, and will continue to flow until fatigue reappears, and the hoightened resistance at the synapse gradually blocks the current once more; if the stimulas be further increased, the flow will recommence.

The nature of this resistance may be primarily due to physical changes in the protoplasm of the synapse, but sooner or later chemical changes must also occur in the nature of a breaking down of the protoplasm; probably every change of resistance at the synapse is a phyoical accompaniment of a chemical change in the nearon. Also, pari passu with changes at the synapse, metabolic processes must occur in the nerve cells, the resistance of various synapses are merely the expression of the normal available energy of the cell; thus, in fatigue is attained a mechanism by which the neuron is protected from all stimuli of ordinary intensity, and thereby an overdraft on the vitality of the nearon is prevented; the most vital neurons must be those which are most frequently in ufs. 
Within the limits of the nutritive capacity of a neuron frequent use with adequate intervals of rest will tend to increase the reserve store of energy in the cell. By some such mechanism as this, by the acquisition of a lower resistance in some than in other neurons, stimali are diverted constantly into the same channels-the channels which offer least resistance to their passage. Thus habits arise and a temperament is built up.

The energy of a neuron is definite in amount; apparently each cell contains a certain amount of protoplasm which is capable of being readily broken up to liberate energy. After its expenditure, further excitation exhausts first the reserve stores of energy in the cell, a process accompanied by a definite structural alteration such as diminution in the number and size of the Nissl's granules, and, if continued, causes the disintegration and diffusion of the nucleue and other phenomena significant of death of the cell. The energy of any neuron may thus be accumalated into several divisions, according to the readiness with which it can be liberated. The ease with which the neuron yields energy from its protoplasm depends upon the degree to which that protoplasm has entered the structural organization of the neuron, hence a resistance at the synapse rises as the demands upon the energy of the cell encroach apon the cell's vitality. So when stimuli of certain intensity have exhausted the energy available for that intensity the synapse blocks the continuance of such stimuli and thus permits anabolic processes to rebuild the reserve of the cell.

In normal life as the day advances the available store of energy is gradually expended, and the resistance at the synapse is slowly raised until towards njght normal stimuli are all but blocked, and the condition known as fatigue is thus developed. Rest follows, the energy reaccumulates in the cell, and the resistance gradually falls. There is thus daily a certain degree of exhaustion, and this process is physiological. It is commonly experienced that the reserve supply of energy of the cell may be considerably encroached upon without pathological results, but then, to ensure a return to the normal nutritive state of the neuron with the special resistance which characterizes it, a more prolonged period of rest is necessary. If now in the absence of adequate rest such a fatigued neuron be again excited, the reserve store of energy of the cell will be still farther depleted; and if this exhausting process of frequently reperted, excessive, or prolonged stimulation is continued without intervals sufficient to permit the neurons to return to their normal state the reserve store of energy in the cell will become exhausted, and the resistance at the synapse will be maintained at a level which effectually blocks all ordinary stimuli ; or the process may even go further, and the organic integrity of the neuron be impaired. The same result may obviously be attained by grossly excessive stimulation for a short period. In everyday lite the gradual dissipation of this neuron energy is seen in cases of chronic strain and its sudden exhaustion in shock. Thus the vitality of the neuron is threatened, and neuropathic states are produced.

Brains differ in their reaction, and this difference we recognize as temperament. The difference in nervous organization is well demonstrated by the action of toxic substances. Quite apart from the difference in cerebral reaction so often observed in acute toxaemias, such as in typhus, this distinction is well exemplified in the diversity of the reactions produced in different individuals to chronic alcohol poisoning. In chronic alcoholic toxaemia the results show themselves in many ways: in some delirium tremens appears, in others progressive cerebral deterioration often accompanied by a tendency to epileptiform seizures, and in others again, apart from slight weakening of control and memory, the stress of action falls on other organs.

The same uncertainty of action is seen from the toxaemia of syphilis; one case develops general paralysis of the insane, another cerebral syphilis, another locomotor ataxia, while a fourth may show no nerve lesions at all. The nervous system in different people must vary in its registive power, and different brains exposed to the same influences are liable to differ in their reaction.

Having now considered the mechanism of cerebral action and of cerebral fatigue, and having shown how prolonged fatigue may merge into a morbid process which requires more than normal physiological rest, or even how under special circumstances the nerve exhaustion may approach to being irreparable, and having further demonstrated that the readiness with which different brains become fatigued is variable, let us now examine M. Déjerine's and M. Babinski's contentions.

Emotion implies expenditure of nerve energy ; prolonged or intense emotions must therefore involve exhaustion. The more frequently they are repeated, the less the interval the nearon is allowed to rebuild its store, the sooner will complete exhaustion be attained. Overwork is merely one form of dissipation of energy, so also is worry, and M. Déjerine's contention that the worry is the more essential factor merely expresses that the overwork must be an intermittent, whereas the worry may be 8 source of continuous degradation of nerve energy. $\mathrm{His}$ further assertion that such chronic causes are more im. portant than sudden causes such as shock, is merely an expression of the relative incidence of chronic strain and shock in any community. The worrying temperament, the constitutional tendency to neurasthenia to which he gave prominence, indicate a quality of ready "fatigability" inherent to such caseg. This inberited quality implies on the part of the synapse a lack of power so to arrange the resistance as to shut off atimuli from a fatigued cell. In such patients resistance at the synapse does not rise pari passu with the work done. The cell is thus exposed to a continual series of small or great demands irrespective of the state of its reserve store of energy; bence the neuron may continue to work till it is quite exhausted. The fault probably lies in the failure of the neuron to incorporate an adequate amount of the protoplasm into its own structure. Thus the protoplasm of the nearon is left in an insufficiently elaborated state, a state of greater chemical instability than is normal, a state therefore which permits of a constant liberation of energy practically as long as any protoplasm remains in the cell.

As regards M. Babinski's contention that such con. ditions as neurasthenia and hysteria were never the result of shock, he dealt with people who from surroundings, occupation, and mission were specially selected on account of their mental stability. He proved that mentally stable people attuned to a shock usually experience it without detriment. This was not under discussion, and was not denied. If stimuli could be devised for M. Babinski's mentally stable individuals of the same relative intensity to them as the exciting stimali were to the patients of M. Déjerine and his followers similar results of shock wonld be observed.

The whole discussion merely emphasizes what I bave already maintained, that there is an inherited or acquired structural predisposition-an emotional diathesis. A more important point clinically is the determination of the atual extent of the lesion, whether it is reparable or not. About this our knowledge is very scanty, and its further investigation is urgently needed.

Taking the mechanism which I have suggested as the mode of origin of neuropathic states, definite indications for treatment necessarily follow. To ensure as complete rest as possible-that is, to ensure the absence of any fresh external stimuli-isolation is necessary. It is not only a means of husbanding the patient's resources, but it has also a certain psycho-therapentic value. To treat accompanying dyspepsias, constipation, sleeplessness, or other symptoms, complete rest in bed in the open aircombined with suitable diet-massage, with baths and electricity, are necessary to eliminate from the disease any accompanying autointoxication and malnutrition. The most favourable conditions for the nutrition of the nervous system of the neurasthenic are bodily health and mental rest. If after these conditions have been main. tained for three months no considerable improvement has been made, the lesion is probably irreparable, and the only hope of amelioration would appear to lie in education, either by suggestion or other psycho-therapeutic measures.

My best thanks are due to Dr. W. J. Maloney for his kind help and suggestions.

ReFrerenoes.

1 L'Encéphale, vol. ii, February 10th, 1910, p. 206 et seq. 2 Froude Short Studies on Great Subjects, vol. i, Spinoza, pp. 341-2. London, 1905. of Mental Science, vol. Ivi, April, 1910, p. 273 . 